\title{
Spatial Transformations of Architect's Workplace Due to Development of Computer Aided Design
}

\author{
Elzbieta Trocka-Leszczynska and Joanna Jablonska \\ Faculty of Architecture, Wroclaw University of Technology, Poland \\ \{elzbieta.trocka-leszczynska, joanna.jablonska\} @pwr.wroc.pl
}

\begin{abstract}
Architects, among other professional groups, are especially involved in the technical development of their occupation at three different levels: designed objects, ways of performing investment processes and methods of current communication. The usage of stationary and mobile computers, graphical tablets, smart phones and other multimedia equipment are currently influencing not only the way of work, but the space of workplaces as well. This paper is aimed at researching this transformation and development. A comparison between two approaches towards a design process will be made, i.e. classical based on a drawing board and modern - with implementation of Computer Aided Design, graphical stations, virtual modeling and multimedia presentations. There will be a discussion on proper measurements and parameters of the workplace in relation to human needs and limitations tested in case studies and in literature examples. Based on conclusions, the guidelines concerning designer's work with the modern electronic equipment will be formulated.
\end{abstract}

Keywords: architect's workplace, workplace with computer, work with multimedia equipment.

\section{Introduction}

From the early conceptual stage of a design to the stage of choosing proper finishing materials a designer comes across varied electronic devices which are involved in his work to a different extent at particular steps. Also methods of presenting and executing each documentation stage have drastically changed in the last decade. The usage of stationary and mobile computers, graphical tablets, smart phones, etc. forces architects not only to pursue their profession in a different way, but also to transform their everyday work environment. However, due to the low ergonomic research development there is a severe misuse of digital appliances which can be inconvenient, harmful and dangerous to the quality of life and work as well as to physical and mental health in the long term. According to literature sources [1, pp. 92, 93], among various threats the following ones can be mentioned: Carpal Tunnel Syndrome, the ulnar nerve groove syndrome, de Guyon canal syndrome, Chronic shoulder periarthritis. Despite the fact that there are some satisfactory guidelines implemented by the European and Polish law concerning human-computer relations, they usually take into account only basic technical solutions. The influence of other electronic appliances should be still 
researched, especially in a narrower field which is architect's work. According to Glegoła [2, p. 28], only $1 \%$ of workplaces equipped with computers are prepared according to requirements as well as rules of ergonomic design.

\section{Aim and Method}

This paper presents a transformation and development by analytical and comparative studies on architect's workplace. A comparison will be made between classical methods of performing designing processes based on a drawing board, hand drawing and a traditional space model execution used in the former decade and modern ways of the project elaboration with implementation of Computer Aided Design, graphical stations, virtual modeling and multimedia presentations. A part of the research will cover the transformation of methods of the building inventory from the measuring tape use towards a laser rangefinder and $3 \mathrm{~d}$ scanner. The investigation will also include architects themselves with a focus on the equipment they mostly use or prefer and how it affects their everyday work. All the three aforementioned aspects will be related to an individual workplace commonly understood as one consisting of a desk, a chair, a telephone and a stationary computer. This definition will be updated to the current standards and expanded on other multimedia equipment necessary to perform professional duties with an additional consideration of managing the investment process. There will also be a focus on threats and inconveniences connected with fast and usually ergonomically unsupervised development of designer tools. Following this aspect and drawing on conclusions, some important guidelines will be formulated concerning designer's work with modern electronic appliances. For each part of the study different methods were used, i.e. for the initial stage and definition formulation - literature research, interviews with professionals, comparative analysis; for case study - photographical documentation, graphical analysis; for final conclusions and future guidelines: analysis, synthesis and comparative analysis.

The issues connected with natural and artificial lighting, microclimate of rooms, psychological factors, acoustical environment, etc. were omitted on purpose in order to focus on material matters which seem to be most neglected in local architectural offices. Moreover, in the light of the executive regulation of the construction law in Poland, the requirements of proper thermal protection of buildings, inner temperature, natural and artificial lighting are commonly respected. Due to the fact that this field of study is so vast and the number of digital equipment available is countless, the presented work has an initial character. The research and measurements were carried out on chosen devices in the field of micro-ergonomics, which was recalled by Nowakowski and Charytonowicz [3, p. 78] as a form of interaction between man and machine. The studies were focused on Polish architectural offices and professionals as well as the available equipment and used in local design studios. Due to this assumption, national regulations were mainly taken into account. It should be stressed that also human measurements may differ due to a nationality and region of origin. 


\section{Discussion}

\subsection{Definition}

A crucial element of the whole studies was to define what should be understood by the architect's material place of work. According to Charytonowicz [4, p. 23], there are three main aspects of factors influencing any type of the workplace: technological, organizational and ergonomic. The first one is connected mainly with the technology and equipment involved, the second one takes into account organization and external factors, while the third one includes adjustments to human needs and physical requirements. It is needless to say that a great transformation can be observed in all of these groups. At present, the main drawing tool of an architect is a computer equipped not only with a keyboard and a mouse, but also with a graphical tablet. It is really important to notice that in the specific work typing takes only a part of the whole time and much more common is drawing with the usage of a mouse, a graphical tablet and very rarely a touchpad. As a part of the discussed definition, an appropriate Polish document was taken into account, namely, 'Regulation of the Minister of Labour and Social Policy of 1 December 1998 on health and safety at workplaces equipped with a display screen' because it refers to a computer as the main device used in modern offices. The above mentioned document [5, p. 5392] describes a workplace as divided into the following elements: basic equipment, additional utensils and service elements. The first one includes a display screen, a keyboard or another input appliance, a central unit or a disk drive (the last one is outdated). For the architect's workplace we should add a graphical tablet. In an additional tool group there are the following devices: a printer, scanner, mouse, trackball, and in this group there should be included a $3 \mathrm{~d}$ scanner and a $3 \mathrm{~d}$ printer (still unpopular on the Polish market) as well as a plotter. According to this regulation, the last group includes service equipment such as a table, chair, footrest and paper holder. The document also mentions software as a part of the work place and other elements that are less relevant to this article. Much more crucial would be to include other work tools which not necessarily have to be plugged into a computer, but they constitute everyday use of electronic appliances such as a mobile phone, laser rangefinder, GPS, etc.

In order to confirm the above mentioned data, several interviews were conducted with individual professional architects of the young generation, i.e. 25-35 years old, working in architectural offices, owning design studios and freelancing. The first question concerned a type of the computer used. Most of the responders emphasized that a unit with a display screen, keyboard and mouse constitute a basic tool in the stationary office work. However, a laptop was mentioned in almost all interviews and there were also declarations that it was the basic equipment at least for additional tasks prepared at home. In the group of everyday use devices, the following were mentioned (listed in order of appearance): printers, plotters, scanners and phones. Apart from these, also the following objects were mentioned: traditional measuring tapes, laser rangefinders, a total station, a tachometer, a leveler, a theodolite, a 3dscanner, digital cameras, digital SLR and digital phone cameras. As for traditional techniques of the architect's work, they are believed to be very useful at an early stage of a design in the form of hand drawing, sketches performed with pencils and markers. Painting techniques such as aquarelle are very rarely used for visualization. As far as a 
drafting table is concerned, only few of the interviewed persons mentioned that they had them; however, were not used in accordance with purpose.

Taking into consideration the aforementioned listings and the individual research, the definition of a modern material architect's workplace is understood as furniture and electronic and digital tools which are fixed as well as mobile used to create a full building-architectural documentation prepared in an investment process. Due to a change of the basic definition, also ergonomic factors have been modified and they will be discussed later on.

\subsection{General Requirements}

According to the previously formulated definition, analysis of the ergonomic aspect of the architects' workplace started from the basic elements and then shifted to minor, yet also important tools. According to the research conducted by Glegoła [2, p. 28], the best way to provide each user with a good solution for his anthropometric characteristics while keeping the furniture in the same style is to use adjustable equipment. The basic parameters which should be regulated are as follows: height of a chair, an armrest and a desk, a tilt of a seat recline, a seat angle and protrusion and the monitor's position. To meet these requirements, manipulation of localization of the keyboard in parameters of height and protrusion should be combined with an operational footrest. The next element would be the possibility of adjusting a distance between recline and seat, a space between armrests and their angles towards the level, together with a modifiable recline curvature supporting the spine, e.g. with the use of a special air pillow [6, p. 55]. Depending on a literature source, the height of the desk should be regulated in a range of $85-60 \mathrm{~cm}$ (top edge) allowing placing its surface on an elbow level of a sitting user. The chair height is ranging from $40-51$ to $36-50 \mathrm{~cm}$ (top edge), tilt of seat recline $-5^{\circ}$ to front and min. $15^{\circ}$ to $30^{\circ}$ to back from a vertical position, the surface of a seat should be movable at an angle with the range of $2-7^{\circ}$ from the level. The armrests in typical chairs are usually situated $20 \mathrm{~cm}$ from the seat surface and should be moved up in a range of $5 \mathrm{~cm}$ while the distance between them should be regulated in a range of $46-51 \mathrm{~cm}$. A seating wideness ought to be between $35-40 \mathrm{~cm}$ and $38-40 \mathrm{~cm}$ deep. The space under the desk should have minimum dimensions of $65 \mathrm{~cm}$ - height, $70 \mathrm{~cm}$ - depth, $70-80 \mathrm{~cm}$ - width. Footrests should be fixed on the floor and their inclination must be regulated in a range of $0-15^{\circ}$. [2, p. 28 , 6, p. 55, 5, pp. 5393-5395, 7, p. 122] According to Grandjean [7, p. 118], the space between the bottom of a desk and the surface of a seating is also important, which should range between $27-30 \mathrm{~cm}$. The author drew attention to the profile of a seating and presented a lot of research with contradictive results. It must be emphasized that the seating parameters must be chosen for each individual separately, however, there are chairs with manually regulated seats in the range of inclination towards back and front. Moreover, some systems flexibly follow the body position adjusting dynamically to each situation, i.e. leaning towards a computer, reclining during a phone conversation, etc.

The next issue involves the proper localization of the computer elements such as a keyboard and a monitor. The former should be placed in a distance of at least $10 \mathrm{~cm}$ from the desk edge and the latter in a distance of 40-75 cm from the user's eyes. The angle of inclination of a monitor from the vertical position should be $20^{\circ}$ to back and 
$5^{\circ}$ to front, and rotate around its axis at least $120^{\circ}$ to $60^{\circ}$ at each side. The screen upper edge should be placed below the user's sight line. The aforementioned regulation [5, pp. 5393-5394] recommends adjusting localization parameters for individual anthropometric features. Glegoła [2, p. 29] further discusses the work with screens of the size equal or larger than $18^{\prime}$ ' with the observation angle in a range between $20-50^{\circ}$. Hands working on a keyboard are usually placed below the working desk plane on a special shelf and they should be underneath or at an angle of $90^{\circ}$ to elbows on armrests of the chair [6, p. 55] The angle of the aforementioned device ought to be regulated in a range of $0-15^{\circ}$ and its total height in at least one position must not exceed $3 \mathrm{~cm}$. [5, p. 5393]

\subsection{Case Studies}

The first case study was carried out on the basis of historical and literature examples of work with the use of a drafting table. Grandjean [7, pp. 30-31] presented different positions of three men of diverse heights working on drafting tables of variety of wideness. The work in a standing position on the improperly regulated board caused a need of 'head to back' relation inclination up to $76^{\circ}$, while in a sitting position it was about $16^{\circ}$. Analyses of drawings show that the regulation was a crucial element of a proper drawing board solution enabling comfortable work in standing and sitting positions along with a recommended foot rest.

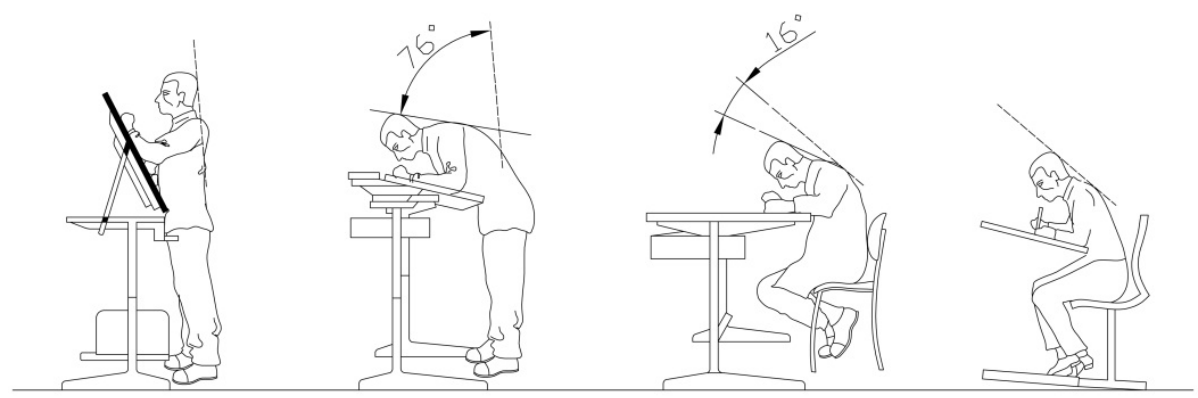

Fig. 1. Work with the use of a drawing board in standing and sitting position. (Elaborated on the basis of [7, p. 31]).

Together with the technological growth, requirements of clients in relation to architects have also changed. Lack of time-consuming hand-drawing needed for preparation of each documentation and easiness in communication - constant availability through mobile phones and the Internet - caused shortening of the documentation execution phase. Another substantial difference would be reduction of paper records to final printing for an administration office or a construction site. Also a form of presentation through rendered visualization forced a designer to use minor mobile electronic devices in order to achieve better communication with a client. Mobility of a designer has also exceeded and it is hard to determine whether portable computers enabled this process or a change in the work organization forced engineers 
to use new technologies. Despite this fact, laptops, notebooks and even tablets have been slowly replacing the aforementioned stationary computers. This process is especially strong when we take into account owners and managers of architectural offices who are less oriented towards drawing work for the benefit of frequent meetings with clients, building and structural engineers or spent a lot of time in administration offices. It is observed that an architect's relation to the technology becomes stronger and has serious implication on all aspects of life as Frejtak [8, p. 13] implies. According to Wachowiak [6, p. 56], mobile computers if used as permanent work devices should be placed as monitors and other parameters must be fulfilled with the use of additional utensils such as a keyboard and a mouse, which is demanded by the aforementioned regulation [5, p. 5393]. However, field studies show that in practice it is hard to find such examples. The aforementioned interviews show that it is crucial to provide architects with the additional space for work with notebooks, net books and laptops at least for the time of presentation, preparation and so on.

Two mobile computers and a stationary one were tested. In all of the three cases the user was observed in the starting consciously straight position and in an unconscious situation after 5-10 minutes of work. The first one was a large laptop with a display screen of 17.3" and general measurements of $28,5 \times 42 \mathrm{~cm}$ with a regular keyboard (standard and numeric) placed $10,7 \mathrm{~cm}$ from the edge and with the height of 3,1 cm measured at the position of " $A$ " key. The monitor of this equipment in the open position is located at least $28,5 \mathrm{~cm}$ from the edge of the device. With the appropriate placement of the computer on the table, the screen can be distanced in a range of 40-55 cm from the user's eyes and these parameters fit in the aforementioned requirements. Within this setting, a comfortable position of hands on a keyboard can be maintained. This element will be placed in the required minimum distance of 10 $\mathrm{cm}$ from the desk edge. During the test, the monitor observation angle was from 31$47^{\circ}$ in a starting position and $33-51^{\circ}$ in the final posture. This data are slightly worse from the recommended ones. Moreover, in the final position a strong and improper inclination of $16^{\circ}$ 'head towards back' relation in comparison with the initial situation was observed. This phenomenon can be related to the lack of monitor's height regulation which forced the screen surface observation at an angle different from $90^{\circ}$ at desirable inclination as set by the user. Moreover, in this case there is no possibility to turn a monitor around its axis. On the tested computer the distance between a monitor and a keyboard cannot be controlled and localization of the unit is always dependable upon the placement of furniture. If the inclination of the keyboard is necessary, the computer supporting pads may be used. Equipping the workplace only with a large laptop may be suitable for a small group of people with certain anthropomorphic characteristic; however, it will not be adjustable for all workers. But even for them limitations of this arrangement may become unbearable during a longer period of time. An additional test was performed with a laptop placed on the user's lap. The 'head towards back' relation changed from the beginning to the finishing position by $25^{\circ}$ and screen's observation angle varied form $49-74^{\circ}$ and all these numbers are far from the recommended ones. The second tested device was a small net book with a display screen of 10.1" and overall measurements of $18,8 \times 26,5 \mathrm{~cm}$ and a minor keyboard distanced at $5,5 \mathrm{~cm}$ from the equipment's edge and $2,1 \mathrm{~cm}$ height at the ' $A$ ' key position with the display of $18,3 \mathrm{~cm}$. While working on the desk it is possible to provide the keyboard position of $10 \mathrm{~cm}$ from the surface edge and a 
display will be distanced about 40-50 cm from the user's eyes, however, the screen observation angle is $40-51^{\circ}$. Due to a display limitation and small keyboard sizes, longer work on this equipment is not recommended. The results were compared with an analysis conducted with the use of a typical stationary computer with a separate monitor of 19', a standardized keyboard and a mouse. The position of the monitor and the keyboard unconsciously chosen by the user was analogical with recommended values and the screen observation angle was $16-28^{\circ}$. The 'head towards back' relation shifted from the starting to end position only by $7^{\circ}$.



Fig. 2. Stationary computer and laptop comparison of starting and finishing positions of user. Regulation options were marked with arrows.


Fig. 3. Head and back inclination during work on laptop and tablet placed on user's thighs. Regulation options were marked with arrows.

In the group of minor equipment the following devices were tested: a laser


graphical tablet (measurements in format of $\mathrm{x}, \mathrm{y}, \mathrm{z}$ ). The analysis of graphical documentation of work with a laser rangefinder did not show any dangerous spine positions. During a longer period of time it is possible that an extended forearm may expose worker's body to hazards. However, in regular architect's activities such onsite measurements constitute only a small part of all assignments. Most of the positions assumed by a worker during work with a laser rangefinder are more comfortable than with measuring tapes. Smartphones, tablets and graphical tablets are operated with hands and due to their size they are kept on the lap. As we can see, the 'head to back' relation inclination changed during the work with Smartphone by $21^{\circ}$, while with a graphical tablet by $22^{\circ}$ from a starting position. This position may be hazardous for health of the spine and back muscles and the amount of time spent on 
activities involving minor digital devices has been on the increase each day. In order to establish a proper position for longer work on a tablet and Smartphone, recommendations for laboratory workplaces with small equipment may become relevant as described by Charytonowicz [4, p. 25]: feet must be resting on the floor or a footrest with their whole surface, a shank and a feet ought to form an angle not less than $90^{\circ}$, a shank and a thigh are located relatively to each other at an angle not less than $90^{\circ}$, the head is slightly inclined to the front, an object is placed at a distance of $30-40 \mathrm{~cm}$ from the eyes. In this position the author mentions three possible hand placements: elbows and forearms are resting on the table, half of the forearm is resting on the work surface or wrists or hands are resting on the table. The last test examined the fingers' position while manipulating minor devices. It showed an unfavorable thumb position while operating bottom left corner keys of both laser rangefinder and Smartphone.
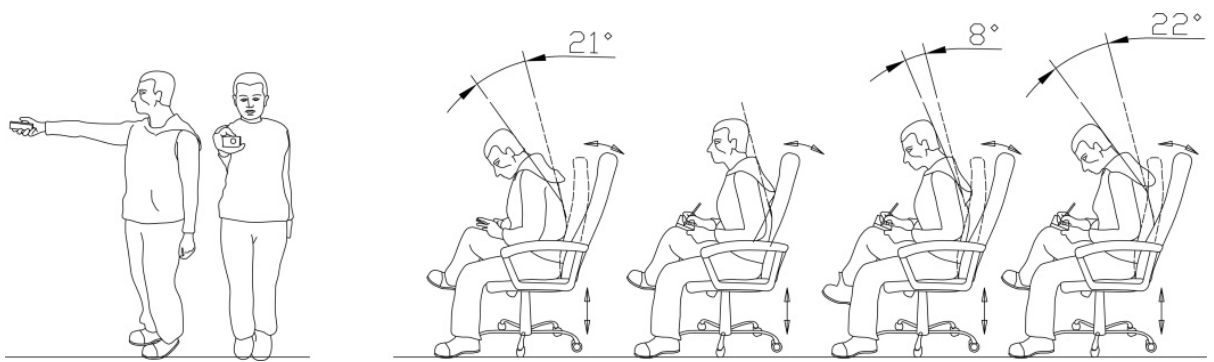

Fig. 4. Work on small devices, from the right: laser rangefinder, Smartphone, graphical tablet starting, middle and final position

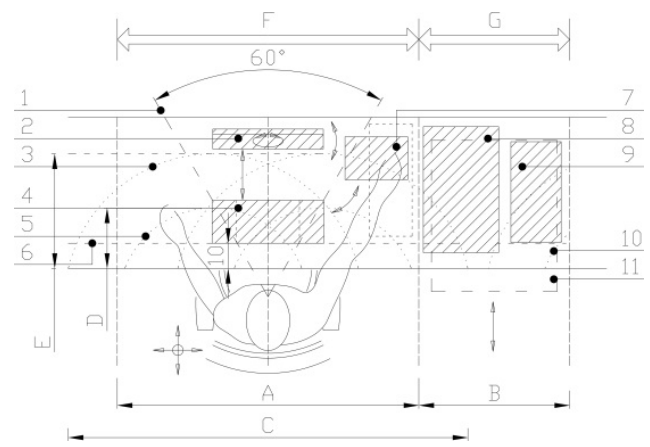

Fig. 5. Workplace recommendation scheme for a drawing architect. (elaborated on the basis of the scheme by Ramsey presented in [4, p. 24]) A - minimal recommended work surface: 120 $\mathrm{cm}, \mathrm{B}$ - minimal recommended common surface: $60 \mathrm{~cm}, \mathrm{C}-$ men: $159 \mathrm{~cm} /$ woman: $145 \mathrm{~cm}, \mathrm{D}$ - men: $24 \mathrm{~cm} /$ woman: $21,5 \mathrm{~cm}, \mathrm{E}$ - men: $45,5 \mathrm{~cm} /$ woman: $40,5 \mathrm{~cm}, \mathrm{~F}$ - individual workplace, $\mathrm{G}$ - common workplace, 1 - convenient visual range, 2 - standard monitor area, 3 maximum hand range, 4 - standard keyboard or graphical tablet area, 5 - normal work hand range, 6 - minimum keyboard from desk edge distance, 7 - standard keyboard or graphical tablet storage area, 8 - typical A4 scanner area, 9 - phones, small equipment, 10 - next work place ranges, 11 - document/paper movable container (on wheels). 


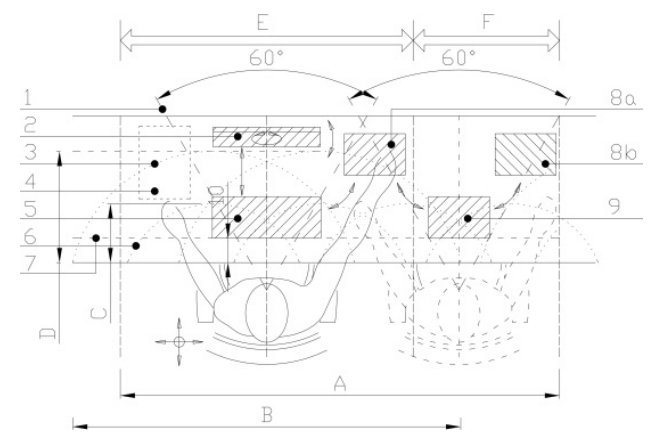

Fig. 6. Workplace recommendation scheme for a managing architect. (elaborated on the basis of the scheme by Ramsey presented in [4, p. 24]) A - recommended work surface: $180 \mathrm{~cm}, \mathrm{~B}-$ men: $159 \mathrm{~cm} /$ woman: $145 \mathrm{~cm}, \mathrm{C}$ - men: $24 \mathrm{~cm} /$ woman: $21,5 \mathrm{~cm}, \mathrm{D}-$ men: $45,5 \mathrm{~cm} /$ woman: 40,5 cm, E - basic workplace, F - additional workplace, 1 - convenient visual range, 2 standard monitor area, 3 - maximum hand range, 4 - additional document space, 5 - standard keyboard area, 6 - normal hand range, 7 - minimum keyboard from desk edge distance, 8 a, b storage space for notebook/net book/tablet, etc., 9 - small equipment workspace tablet/net book /Smartphone, etc.

\section{Conclusions}

In order to design an appropriate place for each architect in the office, we must divide the designers into two groups. The first one includes managers - directors and group leaders whose work is connected with contacting clients and contractors, coordination of office work and project supervision, correction of documentation while preparing concepts and drawing as an additional activity. The second one includes designers and assistants whose responsibility is to prepare all the drawings in documentation with technical descriptions and elaboration of concepts. Concluding, a manager-architect desk should be long $(\mathrm{ca} .180 \mathrm{~cm})$ and enabling work with a lot of small pieces of equipment such as a tablet, a net book, a notebook, a laptop, a Smartphone and other devices placed next to the stationary computer. If the usage of a mobile computer is necessary for a longer period of time, its measurements must be sufficient (minimum 17' screen) and work place furniture must enable regulation. The computer supporting pads are recommended. A very important element would be to provide possibilities of proper work with all the available equipment. A longer desk would enable moving along the equipment, providing proper hand and elbow positioning on the desk while using a Smartphone and a tablet.

For drawing architects there should be an additional storage space enabling quick changes between a graphical tablet and the keyboard. Peripheral appliances placed on desks such as scanners, stationary phones, etc. may occupy a common space assigned to two adjacent employees. Desk printers, faxes and free-standing plotters or $3 \mathrm{~d}$ printers should be placed in a separate room with good ventilation due to a harmful impact of printing media such as inks, toners and others. In both of the described situations a stationary unit should be placed below the desk, on a dedicated shelf on the left desk corner. 
Architects' workplaces have changed a lot since the drawing-board period as well as the specificity of work which is done mainly in a sitting position with the use of digital and electronic equipment. Nowadays it requires various types of computers and constant communication via e-mails, the social media, communicators and telephones. These factors made the architects' workplaces similar to the office ones, however, with one significant difference, namely, a need to use peripheral devices assigned to graphics. Each design and refurbishment process must include these novelties equally in order to select proper furnishing which should be ergonomic and adjustable to varied anthropometrical types. Summing up, health hazards that nowadays can affect architects are greater than they used to be during hand drawing processes and are mainly related to the new minor equipment.

\section{References}

1. Szozda, K.: Architekt a ochrona zdrowia pracowników biurowych. swiat architektury 3(10), 92-93 (2011)

2. Glegoła, P.: Jak połączyłem cztery litery z głową. Zawód:architekt 3, 28-29 (2012)

3. Nowakowski, P., Charytonowicz, J.: Ergonomia pracy i wypoczynku - teraźniejszość i przyszłość. In: Charytonowicz, J., Jasiak, A., Pacholski, L., Rybarczyk, W., Tytyk, E., Marcinkowski, J.S., Ciupik, B. (eds.) Zastosowania ergonomii, Poznań, Wrocław, Zielona Góra, pp. 77-84 (2004)

4. Charytonowicz, J.: Zasady kształtowania laboratoryjnych stanowisk pracy, Oficyna Wydawnicza Politechniki Wrocławskiej, Wrocław (1994)

5. Rozporządzenie Ministra Pracy i Gospodarki Socjalnej z dn. 1 grudnia 1998 r. w sprawie bezpieczeństwa i higieny pracy na stanowiskach wyposażonych w monitory ekranowe, Diary Acts No 148, item 973 (1998)

6. Wachowiak, F.: Ergonomia stanowisk wyposażonych w monitory. Zawód:architekt, 54-57 (March 2012)

7. Grandjean, E.: Ergonomia mieszkania. Aspekty fizjologiczne i psychologiczne w projektowaniu, Arkady, Warszawa (1978)

8. Frejtak, S.: Istota i aspekty ergonomii. In: Charytonowicz, J., Jasiak, A., Pacholski, L., Rybarczyk, W., Tytyk, E., Marcinkowski, J.S., Ciupik, B. (eds.) Zastosowania ergonomii, Poznań, Wrocław, Zielona Góra, pp. 11-17 (2004) 